\title{
Stillbirth at a Nigerian Tertiary Hospital
}

\author{
Owoicho Daniel Okochi, Anthony Dennis Isah*, Teddy Eyaofun Agida, Nathaniel Adewole
}

Department of Obstetrics and Gynaecology, University of Abuja Teaching Hospital, Abuja, Nigeria

Email: *denisanthonyisah@yahoo.com

How to cite this paper: Okochi, O.D., Isah, A.D., Agida, T.E. and Adewole, N. (2018) Stillbirth at a Nigerian Tertiary Hospital. Open Journal of Obstetrics and Gynecology, 8, 756-765.

https://doi.org/10.4236/ojog.2018.88079

Received: June 28, 2018

Accepted: July 24, 2018

Published: July 27, 2018

Copyright $\odot 2018$ by authors and Scientific Research Publishing Inc. This work is licensed under the Creative Commons Attribution International License (CC BY 4.0).

http://creativecommons.org/licenses/by/4.0/ (c) (i) Open Access

\begin{abstract}
Background: Despite improvements in antenatal and intrapartum care, stillbirth still remains an important, largely understudied and pregnant problem in obstetrics. Most of the stillbirths occur in the developing world and the majority of stillbirths are preventable. Objective: To determine the stillbirth rate, the identifiable risk factors and sociodemographic factors associated with stillbirths. Materials and Methods: This was a retrospective review of all deliveries conducted at UATH over a five-year period spanning from the January 2012 to December 2016. In this study, stillbirths were considered as foetal death at or after 28 weeks of gestation or a birth weight of $1000 \mathrm{~g}$ or more. The folders of cases that met the definition of stillbirth within the study period were retrieved and analyzed for sociodemographic factors, type of stillbirth, fetomaternal determinants of stillbirths and presumptive/identifiable risk factors for the stillbirth. Results: There were a total of 5714 deliveries within the period under review, of which 288 resulted in stillbirths giving an institutional stillbirth rate of 50.4/1000 deliveries. Out of the 288 stillbirths, 136 (47.2\%) were fresh stillbirths while 152 $(52.8 \%)$ were macerated. Macerated stillbirth $(152,52.8 \%)$ was slightly predominant, with obstructed labour 94 (32.6\%) being responsible for most of the stillbirths. Most of the stillbirths were preterm (183, 63.5\%). There were 6 congenitally malformed stillbirth foetuses and no autopsy was carried out on any of the 288 stillborn. However, majority of the parturients who had stillbirth were unemployed $(137,47.6 \%)$ and uneducated $(110,38.2 \%)$. Conclusion: The stillbirth rate within the study period appears. Complications of labour seem to be the leading risk factor for stillbirth in this study. Low socioeconomic status underscores the need to reduce factors related to social, educational, occupational and healthy inequalities in the developing world.
\end{abstract}

\section{Keywords}

Stillbirth Rate, Risk Factors, Sociodemographic Factors 


\section{Introduction}

Few obstetric complications are as emotionally devastating for patients, families and clinicians as stillbirth and the grief endured by parents remains untold [1]. Stillbirth has been defined by various countries using gestational age or birth weight. In the United Kingdom (UK), a stillbirth is defined as the delivery of a baby with no signs of life after 24 weeks of pregnancy [2]. However, the World Health Organization (WHO) defines a still birth as the death of a foetus before the complete expulsion or extraction from its mother at term, weighing at least $1000 \mathrm{~g}$ and occurring after 28 weeks of gestation or having at least $35 \mathrm{~cm}$ body length [3] [4]. Stillbirths often go unrecorded and are not seen as a major public health problem. Despite increasing attention and investment on maternal, neonatal and child health, stillbirths still remain invincible, not recorded in the millennium goals, not tracked by the united nations or in the global burden of disease metrics. Rates of stillbirth closely mirror the use and quality of maternal health care services [2]. Stillbirth rates are usually higher in developing countries with poor access and utilization of pre-conception and antenatal health care services [2].

Every year, about 3 million stillbirths occur globally, with almost a third occurring in the intra-partum period [5]. Stillbirth is a public health and developmental problem on the continent with a global incidence of 2.6 million with more than 7178 deaths per day in 2015 [3]. However, the number of stillbirth has declined by $19.4 \%$ between 2000 and 2015, representing an annual reduction rate of 2\% [3]. Almost all stillbirths occur in low and middle income countries [6] [7] [8] [9]. South Asia and sub-Saharan Africa are the largest contributors with over a million and 943,000 stillbirths respectively in 2008 [9]. Stillbirth rate varies sharply from country to country with the lowest rate in Finland of 2 per 1000 births to $42 \%$ - 43\% in Nigeria and highest of 47 per 1000 in Pakistan [2] [10]. Nigeria has the third highest stillbirth burden in the world [5] with stillbirth rates in several studies ranging from 18.1/1000 deliveries to 79.3/1000 deliveries [11] [12] [13].

The causes of a large proportion of stillbirths remain unknown, however, even in cases where extensive testing and autopsy have been performed, only about $40 \%$ of cases were the causes revealed [14]. Globally, two-thirds to three-quarters of stillbirths may occur antenatally before labour begins [15], which are often associated with insults that occur in utero during the antenatal period.

The aetiopathogenesis of stillbirth could be broadly grouped into maternal, foetal or placental origin [16]. The WHO 2015 maternal, new-born, child and adolescent health data, statistics and epidemiology classified the causes of stillbirth into: child birth complications (obstructed labour, ante-partum haemorrhage, cord accidents, uterine rupture), post-term pregnancy, maternal infections in pregnancy (HIV, syphilis, malaria, chorioamnionitis), maternal medical disorders in pregnancy (hypertensive disorders, diabetes, rhesus iso-immunisation, anaemia and obesity), intrauterine growth restriction, congenital anomalies and unknown [3]. Other possible risk factors include: maternal alcohol consump- 
tion, cigarette smoking, radiation poison, physical trauma, extreme of maternal age, low socio-economic status, poor maternal education, nulliparity or grand multiparty and previous stillbirth [4] [7] [8] [9]. Intrapartum stillbirths are usually as a result of undetected and poorly managed foetal distress and or obstructed labour which often reflect inadequate quality of clinical evaluation and monitoring during labour and delivery [17].

The majority of stillbirths are preventable, evidenced by the regional variation across the world. Every new-born action plan (ENAP) to end preventable deaths has set stillbirth target at 12 per 1000 births or less by 2030. Global annual stillbirth reduction rate (ARR) needs to be more than double of the present ARR of $2 \%$ to accomplish this target for reduction of stillbirth [3].

The aims of this study were to determine the stillbirth rate, type of stillbirth, identifiable or presumed risk factors and socio-demographic factors associated with stillbirths.

\section{Materials and Methods}

This was a five-year retrospective study of stillbirths from 2012 to 2016. The record of all deliveries from labour ward register and obstetric theatre were utilized and the case folders of stillbirth deliveries within the study period were retrieved from the central records unit of the university of Abuja teaching hospital. Details were obtained using predesigned questionnaires and analyzed. Stillbirth cases defined by all babies delivered without evidence of life after 28 weeks of gestation and with a weight of $1000 \mathrm{~g}$ or more [3] [8]. The stillbirth rate was defined by number of stillborn/total births X 1000. A fresh stillbirth was defined as the intrauterine death of a foetus during labour or delivery, and a macerated stillbirth was defined as the intrauterine death of a foetus sometimes before delivery (greater than 24 hours), with features suggestive of degenerative changes [12]. All stillbirths with incomplete data files were excluded but included in calculating the rate. The data collected included the information on patient's age, educational status, occupation, marital status and parity, booking status, type of stillbirth, foetal gestational age, birth-weight, presumed risk factors for stillbirth and autopsy records. The occupation of patients were categorized according to the "Dictionary of occupational titles" as; skilled (occupation which requires special skills, training and knowledge (usually acquired) in their work), semi-skilled (occupation requiring more training and skill than an unskilled occupation) and unskilled (occupation requiring no skill or training to perform) [18].

Unbooked status was defined as any patient presenting for the first time at the hospital either in labour or with complications of pregnancy, while booked status is any patient who had supervised pregnancy or has had two or more ANC clinic and has been investigated and classified as a high or low risk patient based on focus antenatal classification.

\section{Results}

There were 5716 deliveries during the period under review; 288 of these delive- 
ries were stillborn, giving an institutional stillbirth rate of 50.4/1000 deliveries. Out of this, 136 (47.2\%) were fresh stillbirths while 153 (52.8\%) were macerated stillbirths. No autopsy was done on the cases reviewed.

The age range was 15 - 44 years and the age group of 30 - 34 years had the highest stillbirth rate of 112 (38.9\%), while those in the age range of 40 - 44 years had the lowest stillbirth rate of 11 (3.8\%). Significantly more stillbirths [202 (70.1\%)] occurred in the unbooked compared to those who were booked [86 (29.9\%)]. Parity of parturient during the study period ranged from 0 - 12. More than half of the stillbirths occurred amongst women of parity 1 - 4 [166 $(57.6 \%)]$. Out of the 288 stillbirth cases, 86 (29.9\%) of them were booked and educational status obtained from their antenatal records revealed a decreasing stillbirth rate with increasing level of education: no formal education $(38.2 \%)$, primary education $(29.2 \%)$, secondary education (19.8\%), and tertiary education (12.8\%). Employment status showed that; 137 (47.6\%) of the women were unemployed and out of the $151(52.4 \%)$ of the employed population, the unskilled occupation category had the highest stillbirths of $86(29.8 \%)$ while the skilled occupation category had the least stillbirths of 31 (10.8\%). Majority of the women were married 259 (89.9\%). Macerated stillbirth accounted for 152 (26.6\%) while fresh stillbirths were 136 (23.2.8\%) (Table 1).

Table 2 showed the majority of the fetomaternal risk factors that occurred, low birth weight contributed highest to the total number of stillbirths 182 (63.2\%) while foetal macrosomia were 23 (8.0\%). Male stillborn 148 (51.4\%) had a slight preponderance than female $140(48.6 \%)$. The pre-term stillborn were 183 (63.5\%), while post-term stillbirth 17 (5.90\%). Congenital malformations accounted for $6(2.1 \%)$ of the total number of stillbirths. No autopsy was carried out. The total number of stillbirth with identifiable risk factors were 199 (69.1\%) while $89(30.9 \%)$ did not have a presumed or identifiable risk factor for the stillbirth. Obstructed labour 94 (32.6\%) was responsible for majority of the stillbirths while gestational diabetes $8(2.8 \%)$ was least. However, other risk factors responsible for stillbirths in this study include, hypertensive disease 64 (22.2\%), antepartum haemorrhage $33(11.5 \%)$, uterine rupture $14(4.8 \%)$, cord accidents $13(4.5 \%)$ and previous history of stillbirth $10(3.5 \%)$.

\section{Discussion}

Stillbirth remains a distressing condition to parents and clinicians alike as the cause often remains elusive. University of Abuja Teaching Hospital is the largest referral hospital serving the Federal capital territory and the neighboring states (Kogi, Niger, Nassarawa and Benue). The hospital stillbirth rate of 50.4/1000 deliveries is comparable with the observed stillbirth rate of 46.9/1000 deliveries reported by Suleiman et al in Kastina Nigeria and 47/1000 deliveries reported in Pakistan [5] [18]. This is in sharp contrast to rates of $2 / 1000$ deliveries and 2.2/1000 deliveries in Finland and Singapore respectively [19]. The stillbirth rate found in this study was higher than the WHO 2009 estimate for Nigeria [5]. 
Table 1. Socio-demographic characteristics.

\begin{tabular}{|c|c|c|}
\hline AGE (YEARS) & NO. OF STILLBIRTH & PERCENTAGE \\
\hline $15-19$ & 22 & $7.6 \%$ \\
\hline $20-24$ & 39 & $13.5 \%$ \\
\hline $25-29$ & 66 & $22.9 \%$ \\
\hline $30-34$ & 112 & $38.9 \%$ \\
\hline $35-39$ & 38 & $13.3 \%$ \\
\hline $40-44$ & 11 & $3.8 \%$ \\
\hline \multirow[t]{2}{*}{ TOTAL } & 288 & 100 \\
\hline & BOOKING STATUS & \\
\hline Unbooked & 202 & $70.1 \%$ \\
\hline Booked & 86 & $29.9 \%$ \\
\hline \multirow[t]{2}{*}{ TOTAL } & 288 & 100 \\
\hline & PARITY & \\
\hline 0 & 69 & $24.0 \%$ \\
\hline $1-4$ & 166 & $57.6 \%$ \\
\hline 5 and above & 53 & $18.4 \%$ \\
\hline \multirow[t]{2}{*}{ TOTAL } & 288 & 100 \\
\hline & EDUCATIONAL STATUS & \\
\hline None & 110 & $38.2 \%$ \\
\hline Primary & 84 & $29.2 \%$ \\
\hline Secondary & 57 & $19.8 \%$ \\
\hline Tertiary & 37 & $12.8 \%$ \\
\hline \multirow[t]{2}{*}{ TOTAL } & 288 & 100 \\
\hline & EMPLOYMENT STATUS & \\
\hline Unemployed & 137 & $47.6 \%$ \\
\hline Unskilled & 86 & $29.8 \%$ \\
\hline Semi-skilled & 34 & $11.8 \%$ \\
\hline Skilled & 31 & $10.8 \%$ \\
\hline TOTAL & 288 & 100 \\
\hline
\end{tabular}

Table 2. Fetomaternal risk factors for stillbirth.

\begin{tabular}{ccc}
\hline FETAL RISK FACTORS & $\begin{array}{c}\text { NUMBER OF } \\
\text { STILLBIRTH }\end{array}$ & PERCENTAGE \\
\hline BIRTH WEIGHT & \\
Low birth weight $(<2.5 \mathrm{KG})$ & 182 & $63.2 \%$ \\
Normal birth weight $(2.5-3.9 \mathrm{KG})$ & 83 & $28.8 \%$ \\
Macrosomia $(\geq 4.0 \mathrm{KG})$ & 23 & $8.0 \%$ \\
TOTAL & 288 & 100 \\
\hline
\end{tabular}




\section{Continued}

\begin{tabular}{ccc}
\hline & GESTATIONAL AGE & \\
Preterm $(<37$ completed weeks) & 183 & $63.5 \%$ \\
Term $(37-42$ weeks $)$ & 88 & $30.6 \%$ \\
Postterm gestation $(\geq 42$ weeks and above $)$ & 17 & $5.9 \%$ \\
Congenital anomaly & 6 & $2.1 \%$ \\
TOTAL & 288 & 100 \\
& MATERNAL RISK FACTORS & \\
Obstructed labour & 94 & $32.6 \%$ \\
Hypertensive disease & 64 & $22.2 \%$ \\
Antepartum haemorrhage & 33 & $11.5 \%$ \\
Uterine rupture & 14 & $4.8 \%$ \\
Cord accidents & 13 & $4.5 \%$ \\
Previous stillbirth & 10 & $3.5 \%$ \\
Diabetes & 8 & $2.8 \%$ \\
No risk & 52 & $18.1 \%$ \\
TOTAL & 288 & $100 \%$ \\
\hline & &
\end{tabular}

Other local studies in Nigeria showed rates of 22.4/1000, 38.5/1000 and 40.5/1000 in Maiduguri, Gombe, and Jos Nigeria respectively and as high as 170/1000 and 180/1000 in Birnin kudu and Enugu respectively [20] [21] [22] [23] [24]. The possible explanation to the high stillbirth in this study may be due to the fact that UATH is a referral centre to many secondary, peripheral hospitals and many maternity homes manned by unskilled traditional birth attendants. To buttress the above, most of the patients in this study (86\%) were unbooked and some referred very late to the teaching hospital with diagnosis of an intrauterine foetal death or when the foetal prognosis was poor. This finding was similar to that in Orlu and shagamu [2] [25]. Being unbooked, these women cannot fully access antenatal care, which includes the detection of women at risk and providing them with specialized care and delivery [26]. WHO has recommended prenatal care as a strategy for improved obstetric care [27].

Slightly more than half of the stillbirths in this study were macerated which is a similar to findings published by several authors [2] [21] [24]. However, this is in contrast to findings from developed countries [3] [6]. The relatively high proportion of fresh stillbirth underscores the need for improved obstetric care and availability of emergency care during labour and delivery in the university of Abuja teaching hospital and most importantly, the referring hospitals. Many factors could be responsible for the differences in the study results. One of the most important factors is the difference in antenatal and intrapartum care in the different settings. Early detection of severe pathologies is more frequent in developed countries than in the developing nations [6] [24]. 
Increasing maternal age and parity have been reported by some authors to be an attributable risk factor in stillbirth due to increased chronic medical conditions which may compromise favourable foetal outcome that are associated with advancing maternal age [5] [8] [22]. This is however in keeping with findings from this study where the highest stillbirth was within the $30-34$ years age range. Most of the stillbirth cases occurred overwhelmingly in the married than in the single group of parturients which is in contrast to findings from some foreign studies [28] which highlighted the risk of stillbirths been associated with single parenting. The contrast in this study can be deduced from the fact that the study area is an African setting where they are sociocultural beliefs that frown at single parenting, so most women prefer to get married before having children. Stillbirth in this study was three times higher in none educated mothers than in highly educated mothers. This is consistent with findings by some authors that showed the associations between educational status and stillbirth rate [29] [30]. Education is an indicator by proxy of socioeconomic status [29].

The employment status from this study is similar to findings by Olof et al. in Sweden that low maternal socioeconomic status is generally associated with increased risk of still births [30]. Low socioeconomic status may connote low funds for adequate maternal nutrition, inadequate prenatal care, low fund for birth preparedness and complication readiness if the need arises. Finally, some women result to home deliveries in a bid to minimize cost. Stillbirth determinant variables noted in this study were similar to those published by Suleiman et al. in Kastina [5].

Amongst the stillbirths within the study period, there was no record of parental consent for autopsy. This may be attributed to the sociocultural and religious beliefs of the Africans in wanting to leave the dead be [4]. In one study, cause of death was found in only $40 \%$ of cases [2]. The summation of the risk factors for stillbirths in this study is similar to most of the publications on stillbirth in the underdeveloped countries with complications of child birth being responsible for most of the stillbirth [2] [4] [5] [17] [20]. It is worthy of note that most of these stillbirth cases were unbooked and mostly referred from peripheral health facilities, maternity homes or after an attempt at home delivery. This finding suggests that there is a need for improved obstetric care and availability of emergency services during the intrapartum period in peripheral hospitals, train traditional birth and adequate health education on antepartum care to discourage home deliveries.

Lack of consent of records on Autopsy was a limitation of this study. Secondly the educational status could only be obtained from the ante-natal records for booked patients because there were no records on the Bio-data form for unbooked patients who came through the obstetric emergency.

\section{Conclusion}

The stillbirth rate within the study period appeared high with the unbooked 
parturient predominating. Low socioeconomic status has a negative influence on stillbirth with complications of child birth being the leading risk factor for stillbirth in this study. These results point out the necessity to reduce factors related to social, educational, occupational and healthy inequalities in the developing world. The major causes of stillbirth in this study are preventable, if good quality antenatal care services and skilled attendance and appropriate care at delivery are made universally acceptable and accessible.

\section{Data Availability Statement}

The data used to support the findings of this study may be released upon application to the human research and ethical committee of the University of Abuja Teaching Hospital, Abuja, Nigeria. For retrospective study, ethical clearance is not required.

\section{Limitation}

One of the limitations to the study was missing data which could not be accountable.

\section{Conflicts of Interest}

The authors declare no conflicts of interest regarding the publication of this paper.

\section{References}

[1] Kiguli, J.S., Munabi, I.G., Segulia, E.S., et al. (2016) Stillbirth in Sub-Saharan Africa: Unspoken Grief. The Lancet, 387, e16-e18. https://doi.org/10.1016/S0140-6736(15)01171-X

[2] Okeudo, C.U., Ezem, B.U. and Ojiyi, E.E. (2012) Stillbirth in a Teaching Hospital in South-Eastern Nigeria: A Silent Tragedy. Annals of Medical and Health Science Research, 2, 176-179. https://doi.org/10.4103/2141-9248.105667

[3] World Health Organisation. (2015) Maternal New-Born, Child and Adolescent Health Data, Statistics and Epidemiology.

[4] McClure, M.E. and Goldenberg, R.L. (2009) Stillbirth in Developing Countries: A Review of Causes, Risk Factors and Prevention Strategies. The Journal of Maternal-Fetal \& Neonatal Medicine, 22, 183-190. https://doi.org/10.1080/14767050802559129

[5] Suleiman, B.M., Ibrahim, H.M. and Abdulkarim, N. (2015) Determinants of Stillbirths in Kastina, Nigeria. Pediatric Reports, 7, 5615-5630. https://doi.org/10.4081/pr.2015.5615

[6] Lawn, J.S., Yakob, M.Y., Haws, R.A., et al. (2009) 3.2 Million Stillbirths: Epidemiology and Overview of the Evidence Review. BMC Pregnancy Childbirth, 9, 52. https://doi.org/10.1186/1471-2393-9-S1-S2

[7] Counsens, S.C., Blencowe, H.W., Staton, C.M., et al. (2011) National, Regional and Worldwide Estimation of Stillbirth in 2009 with Trends since 1995: A Systematic Analysis. The Lancet, 377, 1319-1330. https://doi.org/10.1016/S0140-6736(10)62310-0 
[8] World Health Organisation. (2011) National, Regional and Worldwide Estimates of Stillbirth Rates in 2009 with Trends from 1995.

[9] Lawn, J.S., Blencowe, H.M., Pattinson, R.T., et al. (2011) stillbirths: Where, When, Why? How to Make the Data Count. The Lancet, 377, 1448-1463. https://doi.org/10.1016/S0140-6736(10)62187-3

[10] World Health Organisation. (2011) Current Worldwide Stillbirth Rate.

[11] Adimora, G.N. and Odetunde, I.O. (2007) Perinatal Mortality in University of Nigeria Teaching Hospital, Enugu at the End of the Last Millennium. Nigerian Journal of Clinical Practice, 10, 19-23.

[12] Di, M.S., Say, L.M. and Lincetto, O. (2007) Risk Factors for Stillbirth in Developing Countries: A Systematic Review of the Literature. Sexually Transmitted Diseases, No. 7, 11-21.

[13] Onadeko, M.O. and Lawoyin, T.O. (2003) The Pattern of Stillbirth in a Secondary and a Tertiary Hospital in Ibadan, Nigeria. African Journal of Medicine \& Medical Sciences, 32, 349-352.

[14] Cacciatore, J. (2007) A Phenomenological Exploration of Stillbirth and the Effects of Reutilization on Maternal Anxiety and Depression. University of Nebraska-Lincoln Press Digital Commons.

[15] Goldenberg, R.L., McClure, E.M. and Bann, C.M. (2007) The Relationship of Intrapartum and Antepartum Stillbirths Rates to Measures of Obstetric Care in Developed and Developing Countries. Acta Obstetricia et Gynecologica Scandinavica, 86, 1303-1309. https://doi.org/10.1080/00016340701644876

[16] Silver, R.M., Varner, M.W., Reddy, U.S., et al. (2007) Work-Up of Stillbirth: A Review of the Evidence. American Journal of Obstetrics \& Gynecology, 196, 433-444. https://doi.org/10.1016/j.ajog.2006.11.041

[17] Ukaegbe, U.M., Ikoju, N.S. and Ezegwi, H.U. (2012) Stillbirths at a Tertiary Medical Centre in Enugu, Nigeria. Tropical Journal of Medical Research, 15, 1-4.

[18] (2011) Dictionary of Occupational Titles (DOT).

[19] Hessen, B.R. and Manes, F.C. (2014) Comparison of the Aetiology of Stillbirth over Five Decades in a Sibglecentre: A Retrospective Study. BMJ, 4, e004635.

[20] Audu, B.M., Alhaji, M.A., Takai, U.I., et al. (2009) Risk Factors for Stillbirths at University of Maiduguri Teaching Hospital , Maiduguri, Nigeria: A Cross-Sectional Retrospective Analysis. Nigerian Medical Journal, 50, 42-46.

[21] Alkali, Y.S., Jalo, A.U. and Bode, T.T. (2014) Causes of Stillbirth in a Country Survey in Gombe, Nigeria. AJOL, 41, 2014-2019.

[22] Mutihir, J.T. and Eka, P.O. (2011) Stillbirths at the Jos University Teaching Hospital: Incidence, Risk and Aetiological Factors. Nigerian Journal of Clinical Practice, 14, 14-18. https://doi.org/10.4103/1119-3077.79233

[23] Ugwa, E.A. and Adewale, A.S. (2015) An Assessment of Stillbirth in a Tertiary Hospital in Northern Nigeria. The Journal of Maternal-Fetal \& Neonatal Medicine, 28, 1585-1588. https://doi.org/10.3109/14767058.2014.961416

[24] Bolajoko, O., Solanke, O.A. and Okolo, A.A. (2006) Stillbirth in Sub-Saharan Africa. The Lancet, 368, 117-119. https://doi.org/10.1016/S0140-6736(06)68998-8

[25] Njokanoma, O.F., Sule-odu, A.O. and Akesore, F.A. (1994) Perinatal Mortality at Ogun State University Teaching Hospital Sagamu, Nigeria. Journal of Tropical Pediatrics, 40, 78-81. https://doi.org/10.1093/tropej/40.2.78

[26] Katherine, J.D., Abdul-Razak, S.A. and Boggs, M.S. (2014) An Accurate Marker of 
Time since Intrauterine Foetal Demise in Low-Income Countries. IJOG, 125, 223-227.

[27] World Health Organisation Neonatal (2006) Regional and Global Estimates. WHO, Geneva.

[28] Balayla, J.S. (2011) Maternal Status \& the Risk of Stillbirths and Infant Death: A Population Based Cohort Study on 40 Million Births in the U.S. Women Health Issues, 5, 361-365.

[29] Lawn, J., Shibuya, K. and Stein, C. (2005) No Cry at Birth: Global Estimates of Intrapartum Stillbirths and Intrapartum-Related Neonatal Deaths. World Health Organisation Bulletin, 83, 409-424.

[30] Olof, S. and Dickman, P.W. (2001) The Influence of Socioeconomic Status on Stillbirth Risk in Sweden. International Journal of Epidemiology, 30, 1296-1301.

https://doi.org/10.1093/ije/30.6.1296 